\title{
Residential area deprivation predicts smoking habit independently of individual educational level and occupational social class. A cross sectional study in the Norfolk cohort of the European Investigation into Cancer (EPIC-Norfolk)
}

\author{
S Shohaimi, R Luben, N Wareham, N Day, S Bingham, A Welch, S Oakes, K-T Khaw
}

J Epidemiol Community Health 2003;57:270-276

\begin{abstract}
Objectives: To investigate the independent association between individual and area based measures of socioeconomic status and cigarette smoking habit.

Design and setting: Cross sectional, population based study.

Participants and methods: 12579 men and 15132 women aged 39-79 years living in the general community participating in the EPIC-Norfolk Study in 1993-1997. The association between social class, educational status, Townsend residential deprivation level, and cigarette smoking status was examined.

Main outcome measures: Cigarette smoking status at baseline survey.

Results: Social class, educational level, and residential deprivation level independently related to cigarette smoking habit in both men and women. Multivariate age adjusted odds ratios for current smoking in men were $1.62(95 \% \mathrm{Cl} 1.45$ to 1.81$)$ for manual compared with non-manual social class, $1.32(95 \% \mathrm{Cl} 1.17$ to 1.48$)$ for those with educational level less than $\mathrm{O}$ level compared with those with O level qualifications or higher and $1.84(95 \% \mathrm{Cl} 1.62$ to 2.08$)$ for high versus low area deprivation level. For women, the odds ratios for current smoking for manual social class were $1.14(95 \% \mathrm{Cl} 1.03$ to 1.27$) ; 1.31(95 \% \mathrm{Cl} 1.18$ to 1.46$)$ for low educational level and 1.68 (95\% Cl 1.49 to 1.90$)$ for high residential deprivation respectively.

Conclusions: Residential deprivation level using the Townsend score, individual social class, and educational level all independently predict smoking habit in both men and women. Efforts to reduce cigarette smoking need to tackle not just individual but also area based factors. Understanding the specific factors in deprived areas that influence smoking habit may help inform preventive efforts.
\end{abstract}

See end of article for authors' affiliations

Correspondence to:

Professor K-T Khaw,

Clinical Gerontology Unit,

University of Cambridge,

Addenbrooke's Hospital

Box 251, Cambridge

CB2 2QQ, UK;

kk101@medschl.cam.ac.uk

Accepted for publication 26 September 2002
$\mathrm{R}$ esearch into socioeconomic determinants of health has focused mostly on the effects of individual level exposures on health outcomes. ${ }^{1-5}$ However, several studies $^{6-10}$ have shown that in addition to individual socioeconomic status, the health and lifestyle of a person are influenced by their social and structural environment. ${ }^{7}$ Factors such as substandard housing conditions, differential access to health services, and lack of social organisation have been identified as influencing the health of people living in areas with such characteristics. ${ }^{611} 12$

Many studies have found a higher prevalence of smokers among people of lower socioeconomic status. ${ }^{13-17}$ Some studies have found an association between smoking and area of residence. $^{781819}$ The higher prevalence of smokers in deprived areas could either be explained by the higher numbers of socioeconomically disadvantaged people living in the area ${ }^{20}$ or the effect of the characteristics of the area. ${ }^{11}$ It has often not been possible to separate the effects of individual or area based socioeconomic influences. However, understanding the contributions of individual or area based indicators of socioeconomic status to health may help identify targets for intervention and better strategies to improve health.

We investigated the independent contributions of educational level, occupational social class, and residential area deprivation on smoking habit in a population based cohort of men and women aged 39-79 from the EPIC-Norfolk study.

\section{METHODS}

The population study is based in general practices geographically located in the county of Norfolk and includes the city of Norwich as well as surrounding small towns and rural areas. The cohort was recruited between 1993-1997 as part of the Norfolk component of the European Prospective Investigation into Cancer (EPIC-Norfolk). Detailed descriptions of the recruitment and study methodology have been reported previously. ${ }^{21}$ Men and women aged between 39-79 years identified from collaborating general practice registers were invited by mail to participate. Altogether 30445 participants completed a detailed health and lifestyle questionnaire that included questions on smoking and socioeconomic variables. Cigarette smoking status was derived from the questions "Have you ever smoked as much as one cigarette a day for as long as a year?" and "Do you smoke cigarettes now?". Participants were then categorised as "current smoker", "former smoker", or "never smoker". Social class was classified according to the registrar general's occupation based classification scheme. Social class I consists of professionals, social class II includes managerial and technical occupations, social class III is subdivided into non-manual skilled workers and manual skilled workers, social class IV consists of partly skilled workers, and social class V comprises unskilled manual workers. For men, social class was coded using their own occupation except when they were unemployed or retired in which case their partner's social class was used. Unemployed 
men without partners were unclassified. Social class in women was based on their partner's except when the partner's social class was unclassified, missing, or they had no partner in which case social class was based on their own occupation. An unemployed woman without a partner was coded as unclassified. Educational status was based on the highest qualification attained and was categorised into four groups: degree or equivalent, A level or equivalent, O level or equivalent, and less than $\mathrm{O}$ level or no qualifications.

We used the Townsend Deprivation Index rather than any other index to obtain the residential area based socioeconomic measure as the score does not include occupational social class data. The Townsend score is a composite index used to identify material deprivation and is calculated using a combination of four variables derived from the 1991 census. ${ }^{22}$ The variables used were percentage of economically active residents over 16 years old who are unemployed (a measure of a general lack of material resources and insecurity), percentage of households with no car (a proxy for current income), percentage of households not owner occupied (a proxy indicator of wealth), and percentage of households with more than one person per room (an indicator of material living conditions) - all at the enumeration district level (an enumeration district has an average of about 150 households). Each variable was then standardised by obtaining $\mathrm{Z}$ scores using the mean and standard deviation across the enumeration districts in England and Wales. The Townsend deprivation score at the enumeration district level is derived from the sum of the $\mathrm{Z}$ scores and is relative to England and Wales. The home address at the time of the survey was postcoded. The postcodes were linked to enumeration districts and the deprivation score for the enumeration district was then assigned to the individual. The Townsend deprivation scores for the study population ranged from -6 to +7 with a median of -2.6 . Larger numbers indicate higher level of deprivation. The scores were divided into quintiles with cut off points of $-3.8,-2.9,-2.1$, and -0.55 respectively. Participants with educational level, social class, or Townsend deprivation score missing were excluded as these are the main variables used in this study.

Statistical analyses were performed using SPSS Version 10.0 (SPSS, Chicago, IL). The analyses were undertaken separately for men and women. The proportion of smokers were tabulated according to the three measures of socioeconomic status: social class, level of education, and deprivation level (based on Townsend deprivation index). The $\chi^{2}$ test for trend was used with the $p$ value of $<0.05$ for statistical significance.

The independent effect of area based measure of socioeconomic status on smoking status, adjusted for individual based measures (both social class and level of education) was investigated. The effect of educational level on smoking status adjusted for social class was also investigated. To enable cross stratified analyses using all three indicators, we re-categorised the three socioeconomic status indicators as dichotomous variables. Occupational social class was categorised into nonmanual and manual: social classes I, II, and III non-manual were classified as "non-manual", while social classes III manual, IV, and V were classified as "manual". For area based deprivation, participants with Townsend deprivation scores of $<0$ were categorised as "less deprived", while those with scores above 0 were categorised as "more deprived". Educational level was categorised into "at least O level" (which includes O level, A level, and degree) and "no qualifications".

To compare the independent association between the three socioeconomic status indicators and cigarette smoking status, regression models were conducted including all three variables simultaneously with age. Occupational social class, educational level, and area based deprivation were modelled as categorical variables. A second model was constructed using occupational social class, educational level dichotomously, and the separate components of the Townsend deprivation score. The components of the Townsend deprivation score were dichotomised with those with $\mathrm{Z}$ scores less than 0 in the reference category. A score larger than 0 indicates deprivation (with regard to each component) higher than the average for England and Wales. The separate components of the Townsend deprivation score were included to determine whether any one of the components was important or if it was the effect of a combination of all the variables that made up the Townsend deprivation score. Age was included as a covariate in all the models. Logistic regression was used for cigarette smoking status as binary variables: current smokers compared with non-current (former and never) smokers, where current smoking habit was examined as the dependent variable, or never smokers compared with ever (former and current)

Table 1 Distribution of men and women aged 39-79 years, EPIC-Norfolk cohort, 1993-1997 by social class, educational level, deprivation category, and cigarette smoking status at baseline survey

\begin{tabular}{|c|c|c|c|c|}
\hline \multirow[b]{2}{*}{ Mean age in years (SD) } & \multicolumn{2}{|c|}{ Men $n=12579$} & \multicolumn{2}{|c|}{ Women $n=15132$} \\
\hline & 59.1 & (9.4) & 58.5 & (9.4) \\
\hline Current smokers \% (n) & 12.8 & $(1605)$ & 11.9 & (1777) \\
\hline Former smokers $\%$ (n) & 54.3 & (6793) & 32.1 & (4813) \\
\hline Never smokers \% (n) & 32.8 & (4105) & 56.0 & (8398) \\
\hline \multicolumn{5}{|l|}{ Social class \% (n) } \\
\hline 1 & 7.4 & (935) & 6.1 & $(922)$ \\
\hline$\|$ & 36.7 & (4622) & 33.6 & (5090) \\
\hline III Non-manual & 12.3 & (1549) & 20.2 & (3050) \\
\hline III Manual & 26.4 & (3326) & 21.7 & (3279) \\
\hline IV & 13.8 & $(1742)$ & 13.9 & $(2105)$ \\
\hline $\mathrm{V}$ & 3.2 & $(405)$ & 4.5 & $(686)$ \\
\hline \multicolumn{5}{|l|}{ Educational level \% (n) } \\
\hline Degree or equivalent & 14.6 & (1833) & 10.2 & (1540) \\
\hline A level or equivalent & 45.1 & (5670) & 24.8 & (3760) \\
\hline O level or equivalent & 8.5 & $(1075)$ & 16.0 & (2424) \\
\hline No qualifications & 31.8 & (4001) & 49.0 & (7408) \\
\hline \multicolumn{5}{|c|}{ Deprivation category $\ddagger$ \% (n) } \\
\hline $1(<-3.80)$ & 20.4 & $(2564)$ & 19.9 & (3016) \\
\hline $2(-3.79$ to -2.92$)$ & 21.0 & (2637) & 20.5 & (3105) \\
\hline $3(-2.91$ to -2.09$)$ & 19.0 & (2387) & 19.0 & (2869) \\
\hline $4(-2.08$ to -0.55$)$ & 20.0 & $(2512)$ & 20.2 & (3062) \\
\hline $5(>-0.54)$ & 19.7 & (2479) & 20.4 & (3080) \\
\hline
\end{tabular}




\begin{tabular}{|c|c|c|c|c|c|c|c|c|c|c|c|c|c|c|}
\hline \multirow{3}{*}{\multicolumn{2}{|c|}{ Current smokers }} & \multicolumn{10}{|c|}{ Townsend quintiles } & & & \multirow{3}{*}{$\begin{array}{l}p \text { value for } \\
\text { trend }\end{array}$} \\
\hline & & \multicolumn{2}{|l|}{1} & \multicolumn{2}{|l|}{2} & \multicolumn{2}{|l|}{3} & \multicolumn{2}{|l|}{4} & \multicolumn{2}{|l|}{5} & \multicolumn{2}{|l|}{ Total } & \\
\hline & & $\%$ & $\mathrm{n}$ & $\%$ & $\mathrm{n}$ & $\%$ & $n$ & $\%$ & $\mathrm{n}$ & $\%$ & $\mathrm{n}$ & $\%$ & $\mathrm{n}$ & \\
\hline \multirow[t]{6}{*}{ Men } & By social class & & & & & & & & & & & & & \\
\hline & Non-manual & 8.0 & 132 & 8.8 & 144 & 11.0 & 149 & 9.7 & 132 & 12.9 & 138 & 9.8 & 695 & $<0.001$ \\
\hline & Manual & 14.4 & 130 & 12.5 & 124 & 15.2 & 155 & 15.1 & 171 & 23.7 & 330 & 16.7 & 910 & $<0.001$ \\
\hline & By educational level & & & & & & & & & & & & & \\
\hline & At least $O$ level & 9.2 & 175 & 9.0 & 172 & 12.2 & 200 & 11.4 & 188 & 17.6 & 254 & 11.6 & 989 & $<0.001$ \\
\hline & No qualifications & 13.4 & 87 & 13.5 & 96 & 14.1 & 104 & 13.5 & 115 & 21.1 & 214 & 15.5 & 616 & $<0.001$ \\
\hline \multirow[t]{6}{*}{ Women } & By social class & & & & & & & & & & & & & \\
\hline & Non-manual & 8.9 & 180 & 10.1 & 198 & 10.3 & 177 & 11.2 & 199 & 14.1 & 214 & 10.8 & 968 & $<0.001$ \\
\hline & Manual & 9.9 & 97 & 11.5 & 128 & 12.6 & 141 & 13.3 & 168 & 18.0 & 275 & 13.5 & 809 & $<0.001$ \\
\hline & By educational level & & & & & & & & & & & & & \\
\hline & At least $O$ level & 9.2 & 152 & 9.9 & 168 & 10.6 & 159 & 12.3 & 189 & 13.8 & 174 & 11.0 & 842 & $<0.001$ \\
\hline & No qualifications & 9.4 & 125 & 11.4 & 158 & 12.0 & 159 & 11.9 & 178 & 17.7 & 315 & 12.8 & 935 & $<0.001$ \\
\hline
\end{tabular}

$\ddagger \chi^{2}$ test for trend.

Table 2B Proportion of never smokers by deprivation category and social class and educational level for men $(n=12579)$ and women $(n=15132)$ aged 39-79 years, of the EPIC-Norfolk cohort, 1993-1997

\begin{tabular}{|c|c|c|c|c|c|c|c|c|c|c|c|c|c|c|}
\hline & & \multicolumn{10}{|c|}{ Townsend quintiles } & \multirow{2}{*}{\multicolumn{2}{|c|}{ Total }} & \multirow{3}{*}{$\begin{array}{l}\text { - p value for } \\
\text { trend }\end{array}$} \\
\hline & & \multicolumn{2}{|l|}{1} & \multicolumn{2}{|l|}{2} & \multicolumn{2}{|l|}{3} & \multicolumn{2}{|l|}{4} & \multicolumn{2}{|l|}{5} & & & \\
\hline \multicolumn{2}{|c|}{ Never smokers } & $\%$ & $\mathrm{n}$ & $\%$ & $\mathrm{n}$ & $\%$ & $\mathrm{n}$ & $\%$ & $\mathrm{n}$ & $\%$ & $\mathrm{n}$ & $\%$ & $\mathrm{n}$ & \\
\hline \multirow[t]{6}{*}{ Men } & By social class & & & & & & & & & & & & & \\
\hline & Non-manual & 41.4 & 682 & 37.7 & 614 & 36.9 & 499 & 35.2 & 480 & 32.8 & 352 & 37.2 & 2627 & $<0.001$ \\
\hline & Manual & 33.1 & 299 & 29.7 & 295 & 30.8 & 313 & 25.4 & 287 & 20.4 & 284 & 27.2 & 1478 & $<0.001$ \\
\hline & By educational level & & & & & & & & & & & & & \\
\hline & At least $\bigcirc$ level & 40.9 & 778 & 37.8 & 721 & 37.7 & 617 & 33.2 & 546 & 30.5 & 441 & 36.3 & 3103 & $<0.001$ \\
\hline & No qualifications & 31.3 & 203 & 26.4 & 188 & 26.5 & 195 & 25.9 & 221 & 19.2 & 195 & 25.3 & 1002 & $<0.001$ \\
\hline \multirow[t]{6}{*}{ Women } & By social class & & & & & & & & & & & & & \\
\hline & Non-manual & 60.1 & 1210 & 57.9 & 1138 & 59.3 & 1017 & 54.9 & 976 & 50.4 & 764 & 56.8 & 5105 & $<0.001$ \\
\hline & Manual & 59.8 & 588 & 54.8 & 611 & 55.2 & 618 & 55.8 & 702 & 50.7 & 774 & 54.9 & 3293 & $<0.001$ \\
\hline & By educational level & & & & & & & & & & & & & \\
\hline & At least $\bigcirc$ level & 59.4 & 986 & 59.3 & 1007 & 60.5 & 911 & 55.1 & 849 & 52.2 & 660 & 57.5 & 4413 & $<0.001$ \\
\hline & No qualifications & 60.8 & 812 & 53.8 & 742 & 54.5 & 724 & 55.5 & 829 & 49.4 & 878 & 54.5 & 3985 & $<0.001$ \\
\hline
\end{tabular}

$\ddagger \chi^{2}$ test for trend.

smokers where never smoking was examined as the dependent variable.

\section{RESULTS}

From the total 30445 who completed the questionnaires, 2024 were excluded because of missing Townsend deprivation scores. Data on occupational social class were missing for 612 participants and 96 participants had their social class coded as unclassified while two people had missing values for level of education. These people were also excluded. The present analyses are therefore based on 12579 men and 15132 women. Table 1 shows the baseline characteristics for cigarette smoking status and distribution of participants according to the socioeconomic indicators (occupational social class, level of education, and Townsend deprivation index).

Cross tabulations of deprivation quintiles with social class and educational level as dichotomous variables for cigarette smoking status are shown in table 2. Men and women in manual social classes were more likely to be current smokers compared with those in non-manual social classes. Similarly, men and women with at least $\mathrm{O}$ level qualifications were less likely to be current smokers than those without qualifications.
Even after stratifying for social class or educational level, the influence of area based deprivation on smoking status was evident for both men and women, with a general trend of increasing proportions of current smokers with increasing residential deprivation quintiles (table $2 \mathrm{~A}$ ). Similar patterns in the reverse direction were apparent for never smokers (table $2 \mathrm{~B})$, that is the prevalence of never smokers was highest in men and women living in the least deprived areas.

In multivariate models adjusting for age, independent effects of social class, educational level, and residential deprivation level on cigarette smoking habit were observed in both men and women. Tables $3 \mathrm{~A}$ and $3 \mathrm{~B}$ show age adjusted odds ratios for social class, educational status, and Townsend deprivation quintile when all these were entered simultaneously in the model. In a logistic regression model that examined these variables dichotomously (not tabulated), age adjusted odds ratios for current smoking in men were 1.62 (95\% CI 1.45 to 1.81 ) for manual compared with non-manual social class, 1.32 (95\% CI 1.17 to 1.48 ) for those with educational level less than O level compared with those with O level qualifications or higher and 1.84 (95\% CI 1.62 to 2.08) for high versus low area deprivation level. For women, the odds ratios for current smoking for manual social class were 1.14 (95\% CI 1.03 to 
Table 3A Odds ratio (95\% confidence intervals) for current smokers in 12579 men and 15132 women aged 39-79 years, of the EPIC-Norfolk cohort, 1993-1997 for regression models based on age, social class, level of education, and quintiles of Townsend deprivation index entered simultaneously

\begin{tabular}{|c|c|c|c|c|}
\hline \multirow[b]{3}{*}{ Predictor variables } & \multicolumn{4}{|l|}{ Current smokers } \\
\hline & \multicolumn{2}{|l|}{ Men } & \multicolumn{2}{|l|}{ Women } \\
\hline & $\mathrm{OR}^{*}$ & $p$ value & $\mathrm{OR}^{*}$ & $p$ value \\
\hline \multicolumn{5}{|l|}{ Social class } \\
\hline \multicolumn{5}{|l|}{ I† } \\
\hline II & 1.76 (1.29 to 2.39$)$ & $<0.001$ & 1.43 (1.10 to 1.87$)$ & 0.008 \\
\hline III non-manual & 1.73 (1.23 to 2.44$)$ & 0.002 & 1.60 (1.22 to 2.12$)$ & 0.001 \\
\hline III manual & 2.45 (1.79 to 3.37$)$ & $<0.001$ & 1.51 (1.15 to 2.00 ) & 0.003 \\
\hline IV & 2.48 (1.79 to 3.46$)$ & $<0.001$ & 1.67 (1.25 to 2.22$)$ & $<0.001$ \\
\hline $\mathrm{V}$ & $3.02(2.03$ to 4.48$)$ & $<0.001$ & 1.98 (1.42 to 2.75$)$ & $<0.001$ \\
\hline \multicolumn{5}{|l|}{ Educational level } \\
\hline \multicolumn{5}{|l|}{ Degree } \\
\hline A level & 1.63 (1.32 to 2.01$)$ & $<0.001$ & 1.34 (1.09 to 1.658$)$ & 0.006 \\
\hline O level & 1.73 (1.33 to 2.26$)$ & $<0.001$ & 1.42 (1.13 to 1.771$)$ & 0.002 \\
\hline No qualifications & 1.97 (1.58 to 2.47$)$ & $<0.001$ & 1.67 (1.36 to 2.049 ) & $<0.001$ \\
\hline \multicolumn{5}{|l|}{ Townsend index quintiles } \\
\hline \multicolumn{5}{|l|}{ Quintile $1 \dagger(<-3.8)$} \\
\hline Quintile $2(-3.79$ to -2.92$)$ & 0.98 (0.82 to 1.17$)$ & 0.82 & 1.17 (0.99 to 1.39 ) & 0.07 \\
\hline Quintile $3(-2.91$ to -2.09$)$ & $1.24(1.04$ to 1.48$)$ & 0.02 & $1.23(1.04$ to 1.46$)$ & 0.02 \\
\hline Quintile 4 (-2.08 to -0.55$)$ & $1.14(0.95$ to 1.36$)$ & 0.15 & 1.36 (1.15 to 1.60 ) & $<0.001$ \\
\hline Quintile 5 (>-0.55) & 1.84 (1.56 to 2.17$)$ & $<0.001$ & 1.86 (1.58 to 2.18$)$ & $<0.001$ \\
\hline
\end{tabular}

Table 3B Odds ratio (95\% confidence intervals) for never smokers in 12579 men and 15132 women aged 39-79 years, of the EPIC-Norfolk cohort, 1993-1997 for regression models based on age, social class, level of education, and quintiles of Townsend deprivation index entered simultaneously

\begin{tabular}{|c|c|c|c|c|}
\hline \multirow[b]{3}{*}{ Predictor variables } & \multicolumn{4}{|l|}{ Never smokers } \\
\hline & \multicolumn{2}{|l|}{ Men } & \multicolumn{2}{|l|}{ Women } \\
\hline & OR* & $\mathrm{p}$ value & OR* & $p$ value \\
\hline \multicolumn{5}{|l|}{$\begin{array}{l}\text { Social class } \\
\text { If }\end{array}$} \\
\hline$\|$ & 0.74 (0.64 to 0.86$)$ & $<0.001$ & $0.79(0.68$ to 0.91$)$ & 0.001 \\
\hline III non-manual & $0.68(0.56$ to 0.81$)$ & $<0.001$ & $0.79(0.67$ to 0.92$)$ & 0.003 \\
\hline III manual & $0.56(0.47$ to 0.66$)$ & $<0.001$ & $0.80(0.68$ to 0.93$)$ & 0.005 \\
\hline IV & $0.62(0.51$ to 0.74$)$ & $<0.001$ & 0.77 (0.65 to 0.91$)$ & 0.002 \\
\hline V & $0.57(0.43$ to 0.75$)$ & $<0.001$ & 0.85 (0.69 to 1.05$)$ & 0.13 \\
\hline \multicolumn{5}{|l|}{ Educational level } \\
\hline \multicolumn{5}{|l|}{ Degree $\dagger$} \\
\hline A level & 0.61 (0.54 to 0.69$)$ & $<0.001$ & $0.83(0.74$ to 0.94$)$ & 0.004 \\
\hline O level & $0.55(0.46$ to 0.65$)$ & $<0.001$ & $0.97(0.85$ to 1.11$)$ & 0.67 \\
\hline No qualifications & $0.53(0.46$ to 0.60$)$ & $<0.001$ & 0.83 (0.73 to 0.94$)$ & 0.003 \\
\hline \multicolumn{5}{|l|}{ Townsend index quintiles } \\
\hline \multicolumn{5}{|l|}{ Quintile $1 \dagger(<-3.8)$} \\
\hline Quintile 2 (-3.79 to -2.92$)$ & 0.86 (0.77 to 0.97$)$ & 0.01 & 0.88 (0.79 to 0.97$)$ & 0.01 \\
\hline Quintile 3 (-2.91 to -2.09$)$ & $0.86(0.76$ to 0.97$)$ & 0.01 & 0.91 (0.82 to 1.01$)$ & 0.07 \\
\hline Quintile 4 ( -2.08 to -0.55$)$ & $0.74(0.66$ to 0.84$)$ & $<0.001$ & 0.83 (0.75 to 0.92$)$ & $<0.001$ \\
\hline Quintile 5 (>-0.55) & $0.60(0.53$ to 0.68$)$ & $<0.001$ & $0.69(0.62$ to 0.76$)$ & $<0.001$ \\
\hline
\end{tabular}

1.27); 1.31 (95\% CI 1.18 to 1.46 ) for low educational level and 1.68 (95\% CI 1.49 to 1.90 ) for high residential deprivation respectively.

The independent odds ratios for never smokers in men were 0.69 (95\% CI 0.64 to 0.75 ) for manual compared with non-manual social class, 0.78 (95\% CI 0.71 to 0.85 ) for those with educational level less than O level compared with those with O level qualifications or higher and 0.70 (95\% CI 0.63 to 0.78 ) for high versus low area based deprivation. The odds of never smoking were 0.97 (95\% CI 0.91 to 1.04) for women in manual compared with non-manual social class, 0.91 (95\% CI 0.85 to 0.98 ) for those with low educational level versus high educational level and 0.76 (95\% CI 0.70 to 0.83 ) for those with high area based deprivation. Low residential deprivation area was thus also predictive of never smoking in both men and women, with an effect size in women greater than personal social class and educational level.

The inclusion of individual components of the Townsend deprivation index in the second model did not have any effect on the influence of social class and educational level on being a current smoker (table 4A). In both men and women, those who lived in areas where there is a high percentage of unemployment and households with no car were more likely to be current smokers. Men who lived in areas where there is a higher percentage of unemployment, households with no car, and households not owner occupied were less likely to be 
Table 4A Odds ratio (95\% confidence intervals) for current smokers in 12579 men and 15132 women aged 39-79 years, of the EPIC-Norfolk cohort, 1993-1997 for models based on age, social class, level of education, and components of Townsend deprivation index

\begin{tabular}{|c|c|c|c|c|}
\hline \multirow[b]{3}{*}{ Predictor variables } & \multicolumn{4}{|l|}{ Current smokers } \\
\hline & \multicolumn{2}{|l|}{ Men } & \multicolumn{2}{|l|}{ Women } \\
\hline & OR* & $p$ value & $\mathrm{OR}^{*}$ & $p$ value \\
\hline Social class (non-manual t $v$ manual) & $1.61(1.43$ to 1.80$)$ & $<0.001$ & $1.13(1.02$ to 1.26$)$ & 0.02 \\
\hline Education (at least $O$ level $\uparrow v$ no qualifications) & $1.30(1.16$ to 1.47$)$ & $<0.001$ & 1.30 (1.17 to 1.45$)$ & $<0.001$ \\
\hline Unemploymentł & 1.26 (1.04 to 1.52$)$ & 0.02 & $1.33(1.11$ to 1.60$)$ & 0.002 \\
\hline Households with no carł & 1.50 (1.28 to 1.77$)$ & $<0.001$ & 1.32 (1.13 to 1.55$)$ & $<0.001$ \\
\hline Households not owner occupied $\ddagger$ & $1.14(1.01$ to 1.28$)$ & 0.04 & 1.14 (1.02 to 1.28$)$ & 0.03 \\
\hline Overcrowding $\ddagger$ & $1.10(0.93$ to 1.29$)$ & 0.26 & $1.10(0.94$ to 1.28$)$ & 0.26 \\
\hline
\end{tabular}

*Odds ratio indicates change in probability compared with the reference category. †Reference category. Predictor variables: social classnon-manual=social classes I, II, and III non-manual, manual=social classes III manual, IV, and V. Education-at least $O$ level, no qualifications. $¥$ Reference category-areas with Z score below the average for England and Wales average $(<0)$.

Table 4B Odds ratio (95\% confidence intervals) for never smokers in 12579 men and 15132 women aged 39-79 years, of the EPIC-Norfolk cohort, 1993-1997 for models based on age, social class, level of education and components of Townsend deprivation index

\begin{tabular}{|c|c|c|c|c|}
\hline \multirow[b]{3}{*}{ Predictor variables } & \multicolumn{4}{|l|}{ Never smokers } \\
\hline & \multicolumn{2}{|l|}{ Men } & \multicolumn{2}{|l|}{ Women } \\
\hline & OR* & $\mathrm{p}$ value & $\mathrm{OR}^{*}$ & $\mathrm{p}$ value \\
\hline Social class (non-manual $\dagger v$ manual) & $0.70(0.64$ to 0.76$)$ & $<0.001$ & $0.98(0.91$ to 1.05$)$ & 0.51 \\
\hline Education (at least $O$ level $\dagger v$ no qualifications) & $0.79(0.72$ to 0.86$)$ & $<0.001$ & $0.92(0.85$ to 0.98$)$ & 0.01 \\
\hline Unemploymentł & $0.81 \quad(0.68$ to 0.95$)$ & 0.01 & $0.79(0.69$ to 0.90$)$ & $<0.001$ \\
\hline Households with no carł & $0.85(0.74$ to 0.97$)$ & 0.02 & 0.89 (0.80 to 0.99$)$ & 0.03 \\
\hline Households not owner occupied $\ddagger$ & 0.84 (0.77 to 0.92$)$ & $<0.001$ & $0.96(0.89$ to 1.03$)$ & 0.26 \\
\hline Overcrowding $\ddagger$ & $0.92(0.81$ to 1.05$)$ & 0.23 & $0.90(0.81$ to 1.01$)$ & 0.06 \\
\hline
\end{tabular}

*Odds ratio indicates change in probability compared with the reference category. †Reference category. Predictor variables: social classnon-manual=social classes I, II, and III non-manual, manual=social classes III manual, IV, and V. Education-at least O level, no qualifications. $¥$ Reference category-areas with Z score below the average for England and Wales $(<0)$.

never smokers (table 4B). However, the effect size was smaller compared with social class and educational attainment. In women, unemployment and lack of car significantly predicted being a never smoker with those living in areas of higher unemployment and households with no car less likely to be a never smoker. The strength of association was greater for unemployment and lack of car compared with social class and educational level.

\section{DISCUSSION}

Many studies have investigated the effects of socioeconomic status on health. Most of the studies used single indicators of socioeconomic status such as occupational social class, ${ }^{323-25}$ educational level, ${ }^{26-28}$ or area based measures such as deprivation indices, often with the area based measure used as a surrogate measure for individual social class where this was not available. ${ }^{29-31}$ A few studies that examined the association between both individual and area based measures of socioeconomic status on all cause mortality, ${ }^{20}$ self reported health, ${ }^{32}$ and cardiovascular disease risk factors ${ }^{71933}$ found independent effects of area deprivation after controlling for individual based measures of socioeconomic status. How exactly socioeconomic status affects health outcomes is not well understood but at least some of the effect is thought to be mediated through differences in lifestyles such as diet or cigarette smoking habit.

In this study we found strong independent effects of individual social class, educational status, and residential area deprivation on cigarette smoking habit. The independent effect of residential area deprivation was comparable to that of individual measures of social class and educational status.
It is unlikely that this effect could be explained by selection biases or confounding. The EPIC-Norfolk study was designed as a prospective study so the aim was to recruit a cohort willing to participate in the baseline survey and to be followed up. Though the response rate was about half those mailed and characteristics of participants were somewhat skewed towards the type of persons willing to participate in such studies, as evident from the tables, there was still a wide range of social class, educational status, and residential area deprivation within the cohort. Thus, while the prevalence distribution of social class and deprivation might not be exactly representative of national samples, this would not bias the within cohort relations between smoking and socioeconomic status. In fact, the distribution of social class was not dissimilar to that reported in national surveys. While deprivation based on the mean Townsend score seems to be shifted in a favourable direction in this cohort, the Townsend score uses indices such as car ownership and overcrowded housing, which may be more appropriate for urban environments and may not be sensitive to rural deprivation such as that which occurs in Norfolk. The study design is thus unlikely to produce substantial biases in the relation between socioeconomic status and smoking within the population. The exclusion of people whose social class and deprivation scores were missing or not classified could cause bias only if they differed from those included in the study with respect to the relation between social class and smoking or area based deprivation and smoking, which seems unlikely.

It is also possible that persons of different socioeconomic status or education may report smoking habits differently. However, it is not likely that a person's residential postcode could influence their self reports of smoking habit. In any 


\section{Key points}

- Efforts to stop smoking have traditionally focused on individually based interventions such as psychological therapies, or national approaches such as taxation and advertising.

- In men and women in the general population, residential area deprivation, social class, and educational status all independently predicted smoking habit.

- Residential area deprivation was a strong independent predictor with those living in more deprived areas having one and a half to twice the likelihood of being a current smoker compared with less deprived areas. This effect was comparable to that observed for social class and educational status.

- This may point to more effective local strategies for smoking cessation.

case, relations were generally observed not just for current smoking where more bias might be expected, but also for never smoking status.

Some of the other characteristics of the cohort, in particular the sex differences in educational status may reflect both cohort effects, as many of this cohort were from the wartime generation in whom education was disrupted, and characteristics of rural farming populations. Social class and educational status in women was less strong a predictor of either current or never smoking compared with these variables in men. This may partly reflect more difficulty in classifying social class for women ${ }^{34}$ and also possibly gender differences in the relation between education and smoking habit.

While it is not unexpected that individual social class and educational status should be independently related to smoking status, the effect of residential deprivation was independent of and at least as strong as both these individual measures. This was somewhat surprising given the potential large measurement error with such scores based on crude postcodes within a single region and relatively insensitive indices. We also did not have information on duration of residence so are unable to tell if the relation was more likely to reflect current or past exposures. Nevertheless, the population in Norfolk is comparatively stable compared with elsewhere in the United Kingdom.

It seems probable, therefore, that characteristics of an area in which a person lives may influence their likelihood of either starting smoking or of stopping smoking independent of that person's personal characteristics. Although the characteristics of an area may be important predictors of smoking status, it is also possible that the characteristics are determined by the area's population composition. The concept of area based deprivation however, aims to capture the underlying contextual effect through the use of a combination of deprivation measures, ${ }^{22}$ which could not otherwise be obtained through the aggregation of individual based indicators. Analysis of the separate components of Townsend deprivation score showed that while independent effects were observed for the association between unemployment, lack of car, and smoking status, the effect of a combination of the variables was much stronger than any one variable on its own.

There are several possible explanations for the association observed between living in areas of greater deprivation and a greater likelihood of smoking, despite the effects of mass media and national taxation, legislation, and advertising policies. People who live in an area with a high percentage of unemployment are more likely to be exposed to neighbours who may have different particular behaviours compared with those who live in affluent areas. Studies have shown that people's behaviour is influenced by the norms and values of those around them. ${ }^{35}{ }^{36}$ If smoking is socially acceptable and more prevalent in highly deprived areas, the people living in these areas are more likely to adopt the same lifestyles. The high percentage of households with no car especially in a rural area may suggest that residents are more unlikely to venture beyond their neighbourhood social circle.

The physical environment of the area may play a part in promoting the uptake of smoking. The quality of housing and overcrowding may lead to increasing level of stress and as a result, people turn to smoking as a form of stress reliever. This, coupled with the differential availability of cigarettes may explain the higher prevalence of smoking in deprived areas.

The pathways linking education and health have been discussed previously. ${ }^{32}$ One of the possible pathways entails the role of education in improving health related knowledge, which in turn influences individuals to adopt healthier lifestyles. ${ }^{37}$ However, when examining the association between education and cigarette smoking, Kenkel ${ }^{37}$ found that the influence of education on smoking remains, even after health related knowledge was taken into account. This suggests that there are effects beyond health related knowledge that are involved. This may include differential cultural values.

Despite several decades of awareness of the adverse effects, cigarette smoking is still widely prevalent. Many prevention and cessation programmes focus on either individually based psychological factors, which may be related to individual social class and education or on nationally based policies, such as pricing and taxation of tobacco and advertising. What the particular features are of local environmental factors, as indicated by residential area deprivation, that influence smoking habit, remain to be identified, but the size of the effect indicates a fruitful area for investigation to improve our efforts to reduce cigarette smoking.

\section{ACKNOWLEDGEMENTS}

We thank the participants and general practitioners who took part in the study and the staff of EPIC-Norfolk.

\section{Contributors}

KTK, ND, SB, and NW are principal investigators in the EPIC-Norfolk population study. SO was study coordinator and organised data collection with AW. RL is responsible for data management and computing and data linkages for post coding and assisted with analyses. SS conducted the data analyses and wrote the paper with KTK with contributions from other coauthors. KTK is guarantor for this paper.

\section{Authors' affiliations}

S Shohaimi, R Luben, N Day, Nicholas Wareham, A Welch, S Oakes, K-T Khaw, Institute of Public Health, University of Cambridge, UK

S Bingham, MRC Dunn Human Nutrition Unit, Cambridge, UK

Funding: EPIC-Norfolk is supported by research programme grant funding from the Cancer Research Campaign and Medical Research Council with additional support from the Stroke Association, British Heart Foundation, Department of Health, Europe Against Cancer Programme Commission of the European Union, Food Standards Agency and Wellcome Trust.

Competing interests: none declared.

\section{REFERENCES}

1 Marang-van de Mheen PJ, Davey Smith G, Hart CL, et al Socioeconomic differentials in mortality among men within Great Britain: time trends and contributory causes. J Epidemiol Community Health 1998;52:214-18

2 Davey Smith G, Hart C, Hole D, et al. Education and occupational social class: which is the more important indicator of mortality risk? Epidemiol Community Health 1998;52:153-60.

3 Blane D, Hart CL, Davey Smith G, et al. Association of cardiovascular disease risk factors with socioeconomic position during childhood and during adulthood. BM 1996;313:1434-8.

4 Martikainen $\mathbf{P}$, Lahelma E, Ripatti S, et al. Educational differences in lung cancer mortality in male smokers. Int J Epidemiol 2001;30:264-7.

5 Davey Smith D, Hart C, Blane D, et al. Lifetime socioeconomic position and mortality: prospective observational study. BM 1997;314:547-52.

6 Ellaway A, Macintyre S. Does housing tenure predict health in the UK because it exposes people to different levels of housing related hazards in the home or its surroundings? Health Place 1998;4:141-50. 
7 Reiineveld SA. The impact of individual and area characteristics on urban socioeconomic differences in health and smoking. Int J Epidemiol 1998;27:33-40

8 Dave Smith G, Hart C, Watt G, et al. Individual social class, area-based deprivation, cardiovascular disease risk factors, and mortality: the Renfrew and Paisley Study. J Epidemiol Community Health 1998;52:399-405

9 Ross CE, Mirowsky J. Neighborhood disadvantage, disorder, and health. J Health Soc Behav 2001;42:258-76.

10 Yen IH, Kaplan GA. Poverty area residence and changes in physical activity level: evidence from the Alameda County Study. Am J Public Health 1998;88:1709-12.

11 Macintyre S, Maciver S, Sooman A. Area, class and health: Should we be focusing on places or people? Journal of Social Policy 1993;22:213-34.

12 Robert SA. Community-level socioeconomic status effects on adult health. J Health Soc Behav 1998;39:18-37.

13 de Vries H. Socio-economic differences in smoking: Dutch adolescents' beliefs and behaviour. Soc Sci Med 1995;41:419-24.

14 Townsend J, Roderick P, Cooper J. Cigarette smoking by socioeconomic group, sex, and age: effects of price, income, and health publicity. BM 1994;309:923-927.

15 Graham H, Der G. Patterns and predictors of tobacco consumption among women. Health Educ Res 1999;14:611-18.

16 Stewart MJ, Brosky G, Gillis A, et al. Disadvantaged women and smoking. Can J Public Health 1996;87:257-60.

17 Osler M, Holstein B, Avlund K, et al. Socioeconomic position and smoking behaviour in Danish adults. Scand J Public Health 2001;29:32-9

18 Barnett JR. Does place of residence matter? Contextual effects and smoking in Christchurch. N Z Med J 2000;113:433-5.

19 Kleinschmidt I, Hills M, Elliott P. Smoking behaviour can be predicted by neighbourhood deprivation measures. J Epidemiol Community Health 1995;49:S72-7.

20 Sloggett A, Joshi $\mathrm{H}$. Higher mortality in deprived areas: community or personal disadvantage? BM 1994;309:1470-4

21 Day N, Oakes S, Luben R, et al. EPIC-Norfolk: Study design and characteristics of the cohort. Br J Cancer 1999;80:95-103.

22 Townsend $\mathbf{P}$, Phillimore, $\mathrm{P}$, Beattie, A. Health and deprivation: inequality and the north. London: Croom Helm, 1988.

23 Beer V, Bisig B, Gutzwiller F. Social class gradients in years of potential life lost in Switzerland. Soc Sci Med 1993;37:1011-18.
24 Gregorio DI, Walsh SJ, Paturzo D. The effects of occupation-based social position on mortality in a large American cohort. Am J Public Health 1997;87: 1472-5.

25 Kunst AE, Groenhof F, Mackenbach JP, et al. Occupational class and cause specific mortality in middle aged men in 11 European countries: comparison of population based studies. EU Working Group on Socioeconomic Inequalities in Health. BM 1998;316:1636-42.

26 Schrijvers CT, Stronks K, van de Mheen HD, et al. Explaining educational differences in mortality: the role of behavioral and material factors. Am J Public Health 1999;89:535-40

27 Laaksonen $\mathbf{M}$, Rahkonen O, Prattala R. Smoking status and relative weight by educational level in Finland, 1978-1995. Prev Med 1998;27:431-7.

28 Leclerc A, Pietri F, Boitel L, et al. Level of education, lifestyle, and morbidity in two groups of white collar workers. J Epidemiol Community Health 1992;46:403-8.

29 Ross NA, Taylor SM. Geographical variation in attitudes towards smoking: findings from the COMMIT communities. Soc Sci Med 1998:46:703-17.

30 Tseng $M$, Yeatts K, Millikan R, et al. Area-level characteristics and smoking in women. Am J Public Health 2001;91:1847-50.

31 Pearl M, Braveman P, Abrams B. The relationship of neighborhood socioeconomic characteristics to birthweight among 5 ethnic groups in California. Am J Public Health 2001;91:1808-14.

32 White IR, Blane D, Morris JN, et al. Educational attainment, deprivation-affluence and self reported health in Britain: a cross sectional study. J Epidemiol Community Health 1999:53:535-41.

33 Sundquist J, Malmstrom M, Johansson SE. Cardiovascular risk factors and the neighbourhood environment: a multilevel analysis. Int J Epidemiol 1999;28:841-5.

34 Krieger N, Chen JT, Selby JV. Comparing individual-based and household-based measures of social class to assess class inequalities in women's health: a methodological study of 684 US women. J Epidemiol Community Health 1999;53:612-23.

35 Wang MQ. Social environmental influences on adolescents' smoking progression. Am J Health Behav 2001 ;25:418-25

36 Crane J. The epidemic theory of ghettos and neighbourhood effects on dropping out and teenage childbearing. Am J Sociol 1991:96:1236-59.

37 Kenkel DS. Health behaviour, health knowledge and schooling. Journal of Political Economy 1991;99:287-305. 